\title{
Mind Matters
}

\author{
Slavisa Tasic*
}

\begin{abstract}
"The real trouble with this world of ours is not that it is an unreasonable world, nor even that it is a reasonable one. The commonest kind of trouble is that it is nearly reasonable, but not quite. Life is not an illogicality; yet it is a trap for logicians. It looks just a little more mathematical and regular than it is; its exactitude is obvious, but its inexactitude is hidden; its wildness lies in wait. ... Everywhere in things there is this element of the quiet and incalculable. It escapes the rationalists, but it never escapes till the last moment."
\end{abstract}

Chesterton (1908)

\section{INTRODUCTION}

An increasing number of accounts in recent years have pointed out the difference between two different styles of thinking about the economy. Mankiw (2006) talks about two types of macroeconomists - those who think of economics as akin to engineering and those who would like it to be more like science. Engineers are primarily problem-solvers, while scientists seek to understand the world. In a similar fashion, Boettke, Coyne and Leeson (2006) suggest that economists have gradually assumed the role of high priests, rather than accepting the role of lowly philosophers that their intellectual ancestors once had. Klein (2007) distinguishes the "normal" economist, who follows the norms of established academia and its predominantly formalist mode of discourse, who sees himself as neutral and character-free but is in fact prejudiced against the market, and the "Smith-Hayek" economist, who tends to see the economy as an extremely complex and evolving organism, appreciates the limits of top-down knowledge, is skeptical of government's ability to make improvements on the market, and has a presumption in favor of free markets and individual liberty. Earlier, Buchanan (1964) had suggested that economists should shift focus to studying the market seen as the process of voluntary exchange, from the existing dominant focus on the theory of resource allocation. Hayek (1975) also talks about two types of economists - "puzzlers" are the inquisitive ones, uncertain

* ISM University of Management and Economics, Vilnius, Lithuania, e-mail: slatas@faculty.ism.lt. I would like to thank Zeljka Buturovic, Daniel Klein and the editors of Kyklos for valuable comments on the previous draft.

(C) 2013 John Wiley \& Sons Ltd. 
and suspicious of their own knowledge; whereas "masters", Hayek seems to imply, are prone to a dose of intellectual hubris.

These distinctions go along somewhat different lines but are all broadly compatible. It is generally acknowledged that the difference between two types of attitudes to economic science goes back at least to the Keynesian revolution. Progressivism and its faith in social science and human capability to shape society, the rising ideology of social interventionism and the emergence of macroeconomics in particular, created the need for a specialized discipline and a class of professionals tasked with designing, controlling or tinkering with the market process. The majority of the discipline went that way, but not everyone is comfortable with the dominant paradigm. From the Austrian economists in the 1930s to many economists and a number of influential outsiders today, resistance has not waned.

In this article I want to more closely examine the differences in types of economic thinking and search for their sources beyond the realm of the history of economic ideas and intellectual history in general. Instead, I will relate economic thinking with some well-known findings of neuropsychology and some less well-established conjectures of social psychology. Different attitudes to economic thinking are curiously analogous to two different types of cognitions stemming from the anatomy of the human brain. Without claiming any causal relationships, I will point to the parallels between our brains' alternative cognitive models and some more or less recent trends in economic thinking.

\section{TWO TYPES OF MIND}

The larger context of the said differences in economic points of view has been long familiar. From at least Pascal, if not earlier, distinctions have been made between reason and intuition. Reason, or Pascal's "mathematical" mind, likes clear definitions and distinct ideas, deals well with concepts and categories, but is limited in the face of overwhelming complexity. More thoroughly, Matthew Arnold (1869) famously saw two opposing but concurring and balancing cognitive forces. The first one, Hellenism, is fixated on knowledge, reason and right thinking; the other one, Hebraism, is preoccupied with practice, faith and right conduct. Unlike the Hellenic love for intelligence and abstract theory, Hebraism extols intuition and practical knowledge. Hellenism, with its preference for abstraction, explains the world in a simple and elegant manner, but such clarity and rationality are achieved only by keeping certain difficulties "out of our view." Hebraism knows this and sees logic and reason as shallow, and indeed as a "pride of fools."

The existence of two different epistemic paradigms, defined along similar lines, has therefore been noticed repeatedly in philosophy as well as in economic or social science. Furthermore, it has become well-established in neuroscience 
by now that the two cognitive modes have their physical correlates. Authors and researchers have long hypothesized about the division of the brain and its functions into two relatively separate entities. Earlier philosophical accounts on the two types of thinking and cognition have been accompanied fairly early on by medical claims that the brain consists of two separate entities capable of functioning independently (e.g. Wigan, 1844). And since the 1960s, empirical research on the brain's division into two relatively independent and functionally different hemispheres sprouted, as due to a surgery practiced at the time a number of artificially split-brain people became available for research.

An evolutionary outcome present in other species as well, the physical brain lateralization comes with a number of cognitive consequences. Some early popular conclusions, particularly the attempts to make clear distinctions of what each brain hemisphere does, or to relate brain functions of different hemispheres with personality types, have been largely misguided and lacked support in evidence. According to the number of modern accounts, both hemispheres are involved and work together in performing ordinary mental tasks. What is not questionable anymore is that substantial differences between hemispheres exist and lateralization of brain functions plays a very important role in cognition (Cutting, 1997; Ornstein, 1997; McGilchrist, 2009; Goldberg, 2009).

While the two brain hemispheres complement each other and work best jointly, they are very different in their capabilities and priorities, and therefore specialize in different particular aspects of mental tasks. For example, in speaking, reading and language matters, the left hemisphere deals with grammar, vocabulary and literal meaning, while the right identifies clues from intonation and accentuation in speech and deciphers the less literal and more metaphorical meaning. While the left hemisphere enables us to read the written word, the right hemisphere provides the meaning of the word. Reading is in this sense a common effort, but the tasks of the two hemispheres in the common effort are different. In other mental activities as well, the left hemisphere generally performs tasks in a more literal sense, while the right provides the context. The left hemisphere handles the data, collects and organizes the facts, while the right hemisphere places them in the context, gives them the meaning and makes sense of them (Gazzaniga and LeDoux, 1978).

The left hemisphere is attentive and focused on details but has trouble detaching itself and seeing the whole - it can't see the forest for the trees. The right hemisphere is precisely the opposite - while it misses details, it sees the bigger picture and is better at recognizing broader patterns in objects, events and processes alike.

Likewise, the left hemisphere sees isolated pieces in abstract, outside of the context. Being skilled in abstraction, it is at ease with theory. The right hemisphere is context-oriented and has trouble understanding the data by themselves. Struggling to liberate things from their context, it has trouble digesting highly 
abstract theoretical concepts. The left hemisphere, once the objects are abstracted, proceeds in categorizing objects into classes. The right, unskilled in abstraction and categorization, prefers instead to deal with the real world, living things and concrete individuals. As McGilchrist (2009, p. 352-3) points out, "the right hemisphere is grappling with experience, which is multiple in nature, in principle unknowable in its totality, changing, infinite, full of individual differences, while the left sees only a version or representation of that experience, in which, by contrast, the world is single, knowable, consistent, certain, fixed."

Another property of the left hemisphere is that it prefers to deal with what is already known and is primarily engaged in processing the known data. It prioritizes the expected and does not deal well with the new and unexpected - it sees what it is used to seeing (Goldberg and Costa, 1981). The right hemisphere, on the other hand, handles the new situations better. It is oriented to learning and discovery of new experiences. Because of this difference, their visions in the dynamic context are divergent. In ordinary situations, when extrapolation is good enough as a predictor, the left performs well. However, when prediction is difficult and processes are non linear, the right performs better.

Brain hemispheres are, therefore, complementary and operate with a division of labor. However, the same need for cooperation in performing ordinary cognitive tasks sets two parts of the brain up for a conflict. Equipped with conflicting visions, it is only natural that one hemisphere of the brain inhibits the other (e. g. Chiarello and Maxfield, 1996). By a number of accounts, including the neurological evidence of the left hemisphere physical encroachment and laboratory evidence from split-brain subjects, it appears that the left hemisphere is typically a leader, while the right is the automatic follower (McGilchrist, 2009; Gazzaniga, 2006). Being certain and expressive, left hemisphere is better positioned to inhibit the right, and as far as our cognitive capacities are concerned, this encroachment means the dominance in our thinking and cognition of certain traits characteristic for the left hemisphere. As Gazzaniga (2006) notes, the right hemisphere lacks the ability to express itself - it is the left one that serves as an interpreter for both. And in doing that, it prioritizes its own version of reality, by rationalizing, categorizing and linearizing.

In addition, the relative dominance of the left hemisphere is accompanied with another striking difference between them. The hemispheres have different views of their own capacities: the right hemisphere is the modest one, the left is the hubristic one. The right hemisphere, McGilchrist (2009, p. 80) writes, "acknowledges the importance of ambiguity. It therefore is virtually silent, relatively shifting and uncertain, where the left hemisphere, by contrast, may be unreasonably, even stubbornly, convinced of its own correctness." Being uncertain about its capacity, the right hemisphere is in fact realistic about its own limits. The left lacks this recognition. It is "confident, unreasonably optimistic, unwitting of what goes on in the right hemisphere, and yet in denial about its own limitations" 
(McGilchrist, 2009, p. 131). When lacking information needed to form a proper conclusion the left hemisphere makes a guess - but treats its own mere guess "as a statement of fact" (Gazzaniga and LeDoux, 1978, p. 148). As Cutting (1997, p. 68) puts it, while the left hemisphere shows "an astonishing degree of ignorance" about what the right hemisphere does, it still "abrogates decision-making to itself in the absence of any rational evidence as to what is going on."

Some potentially very important inferences about the dominance have been made by social psychologists. McGilchrist (2009) hypothesizes that the left hemisphere's gradual encroachment on the natural territory of the right has significantly altered our ways of thinking, and points to a number of recent political, artistic and other societal trends in support of the hypothesis. The left-hemisphere's dominance may not have been equal at all times but has changed throughout history. For example, in the ancient Greek world, as well as during the Renaissance period, it appears that the two hemispheres, and consequently two ways of thinking and cognition, were largely in balance. Reason and abstract thinking were accompanied by the intuitive and contextual. On the other hand, the Medieval period - religious, but nevertheless characterized by a strictly rationalistic mode of thinking - and particularly the Enlightenment era and $20^{\text {th }}$ century modernity up to this day, have been the times of the left hemisphere's dominance. Earlier, Ornstein (1972) speculated that the left hemisphere has been increasingly dominant in the Western world. McGilchrist (2009) provides an impressive amount of indirect evidence for the recent rise of the left hemisphere: the growth of Cartesian rationality, tendency for categorization, codification, bureaucracy, modernism in arts and architecture, increased attention on insulated data devoid of theory, are some real world manifestations compatible with the increased left-hemisphere hypothesis.

While brain lateralization and differences in cognitive functions and capacities of the two hemispheres are well-established in modern neurology, any sociopsychological conjecture about the consequences of the dominance of the left hemisphere drawn from there is uncertain. It is likely to remain that way, as it goes beyond neurological science and enters the domain of social sciences and touching upon a number of value judgments. However, the two mindsets repeatedly detected in the ways economists see the world, seem to fit the differences in which the two brain hemispheres operate. Furthermore, the development of economics in the course of the $20^{\text {th }}$ century fits very well with the hypothesis about the rise of the left hemisphere dominance.

\section{RATIONALISM AND REDUCTIONISM}

To exemplify the rise of one, seemingly exact and scientific, thinking pattern in social science at the expense of the other less rigorous and more mundane one, 
let us consider the debate around the so-called "hot hand" phenomenon. Basketball players, coaches and experts traditionally believe that the player may be in a special "hot hand" condition, in which his shooting ability and performance is suddenly elevated. After a player makes several shots in a row, players, coaches and expert commentators tend to believe that his likelihood of making the next shot is higher.

After examining the shooting percentages of several players in a large number of games, Gilovich, Vallone and Tversky (1985) famously showed that the "hot hand" is a myth. Shooting statistics do not in fact show any nonrandom increase in performance; instead, shooting percentages of players tend to revert to the mean. The study has since been universally lauded as an example of the superiority of the hard data approach to conventional wisdom and intuition. ${ }^{1}$

However, a closer inspection of the nature of the data that Gilovich, Vallone and Tversky (1985) use reveals a great degree of reductionism behind them. Shooting attempts are treated as a uniformed category, while they are in reality very diverse. Not all attempts are of equal difficulty, and there seems to be a systematic tendency towards a higher difficulty of the next shots. A player that has made one or two shots is almost always encouraged to shoot more, on his own and by his teammates and coaches. While the first few shots were made from easier positions, each following shot will tend to be attempted from more difficult positions. The opponent's defense pays more attention to the player who has been making shots, which further increases pressure on the shooter. The shooting average of the hot hand shooter will tend to revert to the mean, not because the hot hand does not exist but because it does. The variable that adjusts is not the number of baskets but the audacity to shoot more on the side of the shooter and the intensity of defense on the side of the opponent. ${ }^{2}$

Because of the complexity of the game and the loss of information that happens when basketball game shooting is placed outside its context, abstracted and reduced to data points, basketball players' intuition and common knowledge of this matter may well be superior to the hard data. In fact, the "hot hand" experience is very compatible with the psychological concept of "flow," later proposed by Csikszentmihalyi (1990). An expert faced with a high level of challenge may experience a state of intense and focused concentration, related to

1. Behavioral economics literature widely recognizes the hot hand as a myth (e.g. Camerer 1989).

2. Gilovich, Vallone and Tversky (1985) acknowledge some of these problems and conduct additional tests to eliminate them. They discuss free throws, which do not have some of the elements that make field shots so diverse, such as the choice of position and the defensive pressure - however, players know that free throws are a wholly different matter with its own complexity. While shooting performances are related to some level of excitement, free throw attempts require relaxation and calmness. They also performed a controlled experiment with college level players; however, laboratory conditions are very different than real game conditions and once again the important nuances are lost. 
increased performance. Professionals in many areas, including sports players, have been known to experience such states. As a former professional European and NBA basketball player observes, in such states "the basket seems to you like a bathtub; no, like a swimming pool, and you just cannot miss it."3

It is, therefore, far from obvious that the apparently sound empirical study should overrule the opinions of experienced practitioners. Even though they may well be subject to group-think and other biases, basketball professionals have the intimate, and often probably tacit knowledge of the specificities of this issue. On the other hand, once we attempt to rationally consider the issue, we tend to categorize and reduce the complex events into measurable data, thus overlooking that some potentially relevant knowledge is lost in the process.

In economics, the importance of intimate and context-specific knowledge has been perhaps most famously emphasized by F. A. Hayek (1945) in the argument on the impossibility of socialist planning. Indeed, the most clear exposition of the rationalistic and reductionist, left-hemisphere, view of the economy was the idea that a consciously controlled, centrally planned economy may be superior to the unorganized, chaotic working of the market. What is remarkable about this idea is not that it has been tried and failed in the Soviet Union, but that so many Western economists also saw it as a feasible project (e. g. Bergson et al. 1966; see also Nell 2010). The economy was perceived as largely static, comprehensible and manageable structure. Relationships between variables and coefficients needed for comprehensive economic planning were treated as knowable and data as objective in nature. With the right inputs, the economic problem could be solved in a simultaneous equations model similar to general equilibrium models that had already been present in the economic theory of the time.

By the time of the so-called Socialist Calculation debate about the possibility of central planning, which started in the 1920s and lasted well into the 1940s, economics had already been transformed into a discipline primarily concerned with the allocation of resources. The previous enterprise of political economy, dealing chiefly with the institutional background of economic activity, was being increasingly replaced with the rising formalistic, rationalistic, reductionist, lefthemisphere style of thinking, previously spearheaded by trained engineers such as Walras and Pareto. It was against this intellectual background that market socialist economists were essentially declared the winners in this debate (Schumpeter 1942/1950).

Ludwig von Mises and Friedrich von Hayek, on the other side, claimed that planning is not likely to yield the expected results as the economy is far more complex than the planners seemed to believe (Mises, 1922; Hayek 1937; 1945).

3. The player is Aleksandar Djordjevic, cited in the Serbian newspapers Kurir on May 21, 2007. Translation is mine, the original is available at: http://arhiva.kurir-info.rs/Arhiva/2007/maj/21/SP-0621052007.shtml (accesed on March 7, 2013). 
The nature of the economic problem at stake is not such that scientific planning may solve it. Inputs of production such as capital and labor are not homogenous but in fact very heterogeneous, diverse and non-additive. The economy is not static but continuously changing in unknown directions. Costs and preferences required for planning are neither objective nor knowable outside of the context of the market. Instead, knowledge utilized in the economy is only generated in the market process itself, and as such it is individual, disparate, dispersed, dynamic, and largely non-transferable.

The crucial point, however, is that the problem of economic calculation in society is not only incredibly complex but also deceptively simple. While relying on myriads of ever changing data points of subjective nature, the market process on the outside appears simple and intelligible. The Hayekian political economist would argue that this appearance comes from the order that the market economy spontaneously creates. From the neurologist point of view, however, the undue impression of simplicity is likely to be a function of the left-hemisphere rationalistic reductionism.

More than a mere episode in the history of economic ideas, the socialist calculation debate is an early example of the conflict between two radically different views of economic phenomena. Even modern day graduate textbooks in macroeconomics, following the Arrow-Debreau general equilibrium framework, instruct on solving what is called the "social planner's" problem, with solutions that are supposed to be equivalent to competitive equilibrium solutions. While strictly formal solutions of two alternative allocation procedures may be identical, what is missing in this type of treatment of economic coordination is that the crucial difference between the planner's solution and the competitive process lies in the generation of the otherwise non-existing knowledge via the market process. The supposed equivalence ascribed to the two allocation procedures points to the vision of the economy as both mechanistic, with fixed and clearly defined parts, and unified, goal oriented entity - something that we would expect in a left-hemisphere view in other phenomena. The opposite, right-hemisphere friendly interpretation is that of an organic, fluid, fuzzy, unclear, economy whose characteristics and behavior we are never quite able to pin down.

The subsequent rise of formalism in economics more generally, corresponds to the finding that the left hemisphere strives for clarity and legibility. Formalism makes concepts and relations clear and legible, but in the process also reduces the complex reality to a limited number of intelligible variables and definable relationships between them. What will be sacrificed depends on the relative value that the economist ascribes to the clarity of propositions versus the complexity of economic phenomena. As Kenneth Boulding (1948) pointed out, Shakespeare too may be expressed in formal terms: "Let Hamlet equal $\mathrm{H}$ and Macbeth equal M." The reason we do not do that is that we understand that Hamlet and Macbeth are extremely complex structures, which is why reductionism would in this case 
result in far larger losses of complexity than gains in clarity. In this sense, the economists' attitude to formalism reveals the degree of their appreciation of the underlying complexities of economic phenomena in question. The appreciation of the heterogeneity of concepts such as capital, labor, investment, or government spending, as well as the existence of a multitude of known and unknown relationships that they have with other variables, precludes their aggregation into unified variables and their placement into well-defined functional relationships.

Being part of the larger cognitive, social and intellectual trend, the same attitude that came to dominate theoretical economics found its place in other areas, including both theory and practical finance. Modern financial theory stems from the same reductionist general equilibrium paradigm and shares many of its properties. Abstracting from the context and doing away from arbitrary subjective estimates, it proposes universal rules for financial decision-making based on a limited number of quantifiable and objective criteria.

While Milton Friedman's (1953) methodological work is frequently cited as a milestone for the modern lack of realism in assumptions in economics, in light of the argument presented here the reasons lie deeper, in the reductionist quest for clarity, legibility and uniformity. The assumptions, such as the common knowledge, rationality of agents and the absence of transaction costs, allow modern financial theory to outline the purportedly universal rules of behavior of the financial markets, which in turn yield investing behavior guidelines in the form of quantifiable formulas. Once again, in a trade-off between clarity and complexity, preference is given to clarity. While modern finance has been sometimes accused of complexity of its formulas and product, in fact the opposite is true: what modern finance theory and practice that followed it achieved was the radical simplification of the immensely intricate world of finance.

For example, in the market for mortgage loans, newer banking practices and the regulatory framework that sanctions them place millions of very different individual borrowers within a few well defined categories according to several objective criteria. Earlier direct, detailed and context-specific knowledge about individual borrowers, loans or companies, which banks traditionally relied on, has been replaced by uniformed measures based on correlations between variables. Rather than complicating the world of finance, modern finance theory reduced the immense complexity of the financial practice into several tractable variables.

The traditional credit system was based on decentralized judgment about individual cases. A banker would review the application, often interview the applicant and take into account everything that he could learn about the borrower (Bhide, 2010; Allison 2012). The loan decision thus bore a fair amount of subjectivity, but subjectivity was the price to pay for the knowledge about the particular details of the case. In the meantime, due to the change in the intellectual trends which affected both financial practice and the regulatory framework, 
loan decisions have been largely objectivized. No one makes case-by-case credit judgments anymore, and loan decisions rely on theoretical models that pay little attention to the particulars of each borrower. Internal risk models of large banks, Basel capital adequacy criteria and credit rating agencies all employ similar methods.

The contrast between traditional finance and the modern finance theory which is the primary intellectual basis for both today's financial practice and financial regulation - reveals the different cognitive backgrounds of two approaches. In traditional finance, behavior was largely led by heuristics and practices that have spontaneously emerged and become established over time. As Dowd and Hutchinson (2010) note, the informal rule of traditional finance was a certain wariness towards debt. The utilitarian rationale and moral norm were intertwined within a heuristic that, given a choice, own capital is preferred to debt financing. However, the modern theoretical treatment of debt versus equity dilemma, the Modigliani-Miller theorem, suggests the opposite. On a purely computational basis, there is no difference between equity and debt, and the method of financing is irrelevant for the value of the company. In a similar vein, more traditional risk measures, such as the loss outcome generated by stress tests, are replaced by Value at Risk models for higher tractability and objectivity. While stress tests depend on subjective estimates of the tester, drawing from intuition and experience, Value at Risk models are objective.

Modern finance is, therefore, largely a theoretical enterprise grounded in rationalism, reductionism and objectivism. Long established heuristics and practices, arrived at by trial and error, non-rigorous and with a degree of subjectivity, have been replaced by newly conceived, conscious, formal, clear and objective criteria. And as is the case with other left-hemisphere driven perceptions, it is not only the validity of the reductionist version that is at issue. Rather, in light of the left-hemisphere dominance, the reductionist version is accompanied by the illusion of certainty and disparagement of alternative cognitive modes. The unwarranted reduction of reality into a limited number of tractable objective parameters is accompanied by the excessive reliance on such reductionist version, led by the conviction that this is one true version of reality.

\section{CONCLUSION}

I have argued that the repeated observations made by different economists about two different attitudes, worldviews or mindsets in economics, are fully justified. Moreover, these divisions are not an internal academic issue that begins and ends within economics, but rather a manifestation of a larger, older and more fundamental distinction between two types of minds, also well-documented in neuroscience. Some of the more discussed manifestations of the rationalistic and 
reductionist style of thinking, also characteristic for the left brain hemisphere, have been formalism and naïve empiricism in methodology, and rationalist constructivism in policy. Why this type of thinking became predominant is a much larger question. However, I propose that the roots of the change could lie beyond economics and beyond the history of ideas and political ideologies - and that some clues may be found in cognitive psychology and neuroscience.

A number of other related or independent influences may have been instrumental in the discussed developments in economics. The elevated status of science since the progressive era and the consequent advent of what Hayek (1942) dubbed "scientism" is one possible cause. However, scientism is itself a plausible outcome of the left-hemispheric cognitive style and its introduction simply moves us one step further in the explanatory chain. Another obvious remark would be that the changes in economics corresponded to the political changes in the beginning of the $20^{\text {th }}$ century, such as the growth of government intervention in the economy and the rising needs of the interventionist state for expert planners and policymakers. This, however, does not explain the rise of areas such as modern finance. The changes observed and discussed here have been present across the board, irrespective of political implications and the neuropsychological hypothesis proposed here is their plausible common denominator.

Similar developments have been pointed out in other areas, with or without invoking their association with brain lateralization. McGilchrist (2009) connects the hemispheric differences to a number of phenomenological arguments and relates them to some modern artistic and societal changes. Scott (1998) critiques the tendency towards reductionism and legibility associated with the advent of modernism. The growth of the bureaucratic state, the increased categorization of people and concepts and the rise of rational urban planning with its preference for straight lines and large boulevards are some possible manifestations of the largely left-hemispheric cognitive style. The rise of the codified, statutory law, as opposed to the earlier dispersed and fragmentary case-based law ever since the $19^{\text {th }}$ century, could be a legal aspect of the same tendency (e. g. Couyoumdjian, 2008).

Although I dealt with the division of economics into two camps, it is perhaps more accurate to say that in the $20^{\text {th }}$ century we have witnessed a persistent trend of increasing rational reductionism in economics. Marshall (1890, p. ix) warned about "a temptation to classify economic goods in clearly defined groups, about which a number of short and sharp propositions could be made, to gratify at once the students' desire for logical precision, and the popular liking for dogmas that have the air of being profound and yet easily handled." Following William James, Frank Knight (1924/1999, p. 7) wrote of the human experience of the world as a "big, buzzing, booming confusion," which does not fit well with the "purely intellectual craving for a world which is fixed, and hence can be known, 
once and for all" (Knight, 1925/1999, p. 123). Several decades later, however, Robert Lucas (1980, p. 697) was writing: "On this general view of the nature of economic theory then, a 'theory' is not a collection of assertions about the behavior of the actual economy but rather an explicit set of instructions for building a parallel or analogue system - a mechanical, imitation economy." Whereas Keynes (1936, p. 298) wrote of the economists losing sight of the "complexities and interdependencies of the real world in a maze of pretensions and unhelpful symbols," Lucas (2001/2004, p. 279) declared: "Economic theory is mathematical analysis. Everything else is just pictures and talk."

As Posner (2009) recently pointed out, there are some striking similarities between two economists that are otherwise considered to be polar opposites Ronald Coase and John Maynard Keynes. Free-marketer and micro-economist extraordinaire Ronald Coase has more in common with the left-leaning macro interventionist John Maynard Keynes than either of them has with their modern counterparts. Posner notes that the tendency of today's economists is to take their field to be the study of rational choice, while Coase and Keynes shared the older view that economics is the study of the real life economy, applied assumptions that seemed realistic and relied on a variety of analytical methods. While Coase's and Keynes's economics was largely non-formal and at times non-rigorous, it was, in Posner's words, "commonsense economics".

The differences between the economists in the ways they see the world should not be rashly attributed to their personal cognitive differences. As mentioned before, the view that individuals are characterized by inclinations for different types of cognition is wanting of evidence and has been largely discarded by the subsequent advances in cognitive neuroscience. The difficulty is even greater having in mind that political ideology, by and large, also does not seem to play a decisive role. Generally, in the matters of political economy and macroeconomics, proponents of the conscious and purposeful control of the economy tend to be closer to rationalistic reductionism. Controllability and legibility of the world go hand in hand, but it is difficult to discern the cause and the consequence - whether the reductionist worldview makes control look desirable, or the ideological desire for control reinforces the reductionist tendencies already present in parts of our brains. Moreover, in cases of finance, the ideological relationship seemed to be opposite - it was the proponents of free market economy who advanced the reductionist models.

\section{REFERENCES}

Allison, John (2012). The Financial Crisis and the Free Market Cure: Why Pure Capitalism Is the World Economy's Only Hope. New York: McGraw Hill.

Arnold, Matthew (1869/2006). Culture and Anarchy: An Essay in Political and Social Criticism. New York: Oxford University Press. 
Bergson, Abram, Alexander Erlich, Herbert S. Levine, Warren G. Nutter, Stanislaw Wellisz and Henry L. Roberts (1966). Soviet Economic Performance and Reform: Some Problems of Analysis and Prognosis (A Round-Table Discussion), Slavic Review. 25: 222-246.

Bhide, Amar (2010). A Call for Judgment. Sensible Finance for a Dynamic Economy. New York: Oxford University Press.

Boettke, Peter, Christopher Coyne and Peter Leeson (2006). High Priests and Lowly Philosophers: The Battle for the Soul of Economics, Case Western Reserve Law Review. 56: 551-568.

Boulding, Kenneth (1948). Samuelson's Foundations: The Role of Mathematics in Economics, Journal of Political Economy. 56: 187-199.

Buchanan, James (1964). What Should Economists Do? Southern Economic Journal. 30: 213-222.

Camerer, Colin (1989). Does the Basketball Market Believe in the 'Hot Hand'? The American Economic Review. 79: 1257-1261.

Chesterton, Gilbert K. (1908). Orthodoxy. New York: Dodd, Mead \& Co.

Chiarello, Christine and Lisa Maxfield (1996). Varieties of interhemispheric inhibition, or how to keep a good hemisphere down, Brain and Cognition. 30: 81-108.

Couyoumdjian, Juan Pablo (2008). An Expert at Work: Revisiting Jeremy Bentham's Proposals on Codification, Kyklos. 61: 503-519.

Csikszentmihalyi, Mihaly (1990). Flow: The Psychology of Optimal Experience. New York: Harper and Row.

Cutting, John (1997). Principles of Psychopathology: Two Worlds - Two Minds - Two Hemispheres. Oxford: Oxford University Press.

Dowd, Kevin and Martin Hutchinson (2010). Alchemists of Loss: How Modern Finance and Government Intervention Crashed the Financial System. Chichester: Wiley.

Friedman, Milton (1953). The methodology of positive economics, in: Milton Friedman, Essays in Positive Economics. Chicago: University of Chicago Press: 3-43.

Gazzaniga, Michael (2006). Ethical Brain: The Science of Our Moral Dilemmas. New York: Harper Perennial.

Gazzaniga, Michael and J.E. Joseph LeDoux (1978). The Integrated Mind. New York: Plenum Press.

Gilovich, Thomas, Robert Vallone and Amos Tversky (1985). The Hot Hand In Basketball: On The Misperception of Random Sequences, Cognitive Psychology. 17: 295-314.

Goldberg, Elkhonon (2009). The New Executive Brain: Frontal Lobes in a Complex World. NY: Oxford University Press.

Goldberg, Elkhonon and Louis Costa (1981). Hemisphere differences in the acquisition and use of descriptive systems, Brain and Language. 14: 144-173.

Hayek, Friedrich A. (1937). Economics and Knowledge, Economica. 4: 33-54.

Hayek, Friedrich von (1942). Scientism and the Study of Society, Economica. 9: 267-291.

Hayek, Friedrich A. (1945). The Use of Knowledge in Society, The American Economic Review. 35: 519-530.

Hayek, Friedrich A. (1975/1991). Two Types of Mind, in Friedrich A. Hayek, The Trend of Economic Thinking. London: Routledge and Chicago: University of Chicago Press: 49-55.

Keynes, John Maynard (1936). The General Theory of Employment, Interest, and Money. Cambridge: Macmillan and Cambridge University Press.

Klein, Daniel (2007). The Smith-Hayek Economist: From Character to Identity, Economic Affairs. 27: 91-95.

Knight, Frank (1924/1999). The Limitations of the Scientific Method in Economics, in Ross Emmett (ed.), Selected Essays by Frank Knight, vol. 1: “'What is Truth' in Economics?” Chicago: University of Chicago Press: 1-39.

Knight, Frank (1925/1999). Facts and Metaphysics in Economic Psychology, in Ross Emmett (ed.), Selected Essays by Frank Knight, vol. 1: " 'What is Truth' in Economics?” Chicago: University of Chicago Press: 112-132. 


\section{SLAVISA TASIC}

Lucas, Robert (1980). Methods and Problems in Business Cycle Theory, Journal of Money, Credit and Banking. 12: 696-715.

Lucas, Robert (2001/2004). "Professional Memoir," in William Breit and Barry T. Hirsh (eds.), Lives of the Laureates, $4^{\text {th }}$ ed, Cambridge: MIT Press: 273-298.

Marshall, Alfred (1890/1920). Principles of Economics. London: Macmillan and Co.

McGilchrist, Iain (2009). The Master and His Emissary: The Divided Brain and the Making of the Western World. New Haven: Yale University Press.

Mankiw, Gregory (2006). The Macroeconomist as Scientist and Engineer, NBER Working Paper No. 12349.

Mises, Ludwig von (1922/1981). Socialism: An Economic and Sociological Analysis. Indianapolis: Liberty Fund.

Nell, Guinevere (2010). Rediscovering Fire: Basic Economic Lessons From The Soviet Experiment. New York: Algora.

Ornstein, Robert (1972). The Psychology of Consciousness. New York: Viking.

Ornstein, Robert (1997). The Right Mind: Making Sense of the Hemispheres. San Diego: Harcourt Brace \& Company.

Posner, Richard (2009). Keynes and Coase, Paper prepared for a conference on "Markets, Firms and Property Rights: A Celebration of the Research of Ronald Coase" held at the University of Chicago Law School on December 4-5, 2009.

Scott, James C. (1998). Seeing Like a State: How Certain Schemes to Improve the Human Condition Have Failed. New Haven: Yale University Press.

Schumpeter, Joseph A. (1950/1942). Capitalism, Socialism, and Democracy. New York: Harper \& Row.

Wigan, Arthur L. (1844). The Duality of the Mind. London: Longman, Brown, Green and Longmans.

\section{SUMMARY}

This paper argues that two different worldviews may be identified in economics and hypothesizes about the origins of this differentiation. I argue that the differences in economic worldviews go beyond technical academic, methodological or ideological distinctions; instead, they may be related to both old conceptions of the two types of mind and some newer findings in cognitive neuroscience. In particular, I analyze the recent developments in economics from the brain lateralization point of view and argue that some salient trends in economic thought are largely compatible with the hypothesis of the increased left brain hemisphere dominance. 